\title{
Violência contra mulheres nos livros didáticos de História (PNLD 2018)
}

\author{
Susane Rodrigues de Oliveira' (D) 0000-0003-3139-6231 \\ 'Universidade de Brasília, Brasília, DF, Brasil. 70910-900 - his@unb.br
}

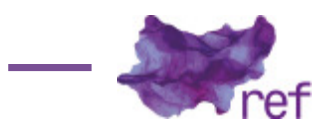

\begin{abstract}
Resumo: No artigo são analisadas as representações de violência contra mulheres em cinco livros didáticos de História, aprovados no PNLD de 2018 para o Ensino Médio. Trata-se de uma abordagem discursivadas representações, atenta à historicidade de suas elaborações, discursos, valores, sentidos e modos de funcionamento no conhecimento histórico a ser ensinado e aprendido nas escolas. $A$ ordem discursiva e epistêmica em que se inscrevem tais representações promove modos de subjetivação e maneiras ver, pensar, sentir e tratar essa violência no tempo presente. Baseando-se em estudos feministas interseccionais, propõe leituras e abordagens possíveis das narrativas didáticas em sala de aula, tendo em vista um ensino de História para o combate à violência contra mulheres.

Palavras-chave: violência; mulheres; interseccionalidades; livro didático; ensino de História
\end{abstract}

Violence against Women in History Textbooks (PNLD 2018)

Abstract: The article analyzes the representations of violence against women in five History textbooks approved in the PNLD of 2018 for High School.It is a discursive approach to representations, attentive to the historicity of their elaborations, discourses, values, senses and modes of functioning in the historical knowledge to be taught and learned in schools. The discursive and epistemic order in which such representations are inscribed promotes modes of subjectivation and ways to see, think, feel and treat this violence in the present time. Based on intersectional feminist studies, presents readings and possible approaches to didactic narratives in the classroom, with a view to teaching history to combat violence against women.

Keywords: Violence; Women; Intersectionalities; Textbook; Teaching History.

\section{Introdução}

Este artigo apresenta os resultados de uma pesquisa sobre representações de violência contramulheresem cinco livros didáticos de História, aprovados no Programa Nacional do Livro Didático (PNLD) de 2018 para o Ensino Médio. Metodologicamente, optamos por uma abordagem discursiva das representações, atenta à historicidade de suas elaborações, discursos, valores, normas, sentidos e modos de funcionamento no conhecimento histórico a ser ensinado e aprendido nas escolas. As representações dizem respeito à produção de sentidos pela linguagem, ao modo como atribuímos sentidos às coisas - pelas "palavras que usamos para nos referir a elas, as histórias que narramos a seu respeito, as imagens que delas criamos, as emoções que associamos a elas, as maneiras como as classificamos e conceituamos, enfim, os valores que nelas embutimos" (Stuart HALL, 2016, p. 21).Trata-se de um conjunto de imagens, ideias, esquemas e categorias que "permitem sentir, refletir e, portanto, interpretar o mundo de forma semelhante" (HALL, 2016, p. 23). Como elementos constitutivos da linguagem - adquirida por meio das interações e experiências sociais, e por meio de veículos difusores de cultura, tais como a mídia televisiva, a ciência, a historiografia, o cinema, a literatura, a escola e os próprios livros didáticos -, as representações são capazes de regular e organizar nossas práticas e condutas, de intervir na construção das identidades e na demarcação das diferenças, auxiliando "no estabelecimento de normas e convenções segundo as quais a vida em sociedade é ordenada e administrada" (HALL, 2016, p. 22). 
Não por acaso, a imagem que uma determinada sociedade constrói sobre si mesma, das subjetividades no tempo presente e de seu projeto de futuro depende, sobretudo, das representações que ela produz acerca do passado (Fernando COSTA, 2009, p. 285). Ao conectar passado, presente e futuro, as representações históricas fornecem sentidos, referências e orientações para nossas experiências no tempo (COSTA, 2009), constituindo-se em importantes dispositivos de subjetivação (construção de sujeitos). Desse modo, a atribuição de sentidos ao presente ocorre também a partir de modos de apropriação e interpretação de experiências do passado, pois muitas vezes a memória e a história são mobilizadas na re-afirmação ou formação de subjetividades.

A noção de subjetividade permite compreender melhor a dinâmica dos processos de construção dos sujeitos, pois a identidade nunca é fixa ou imutável, pelo contrário, se constitui em um processo de construção permanente nas interações do sujeito no meio social. Segundo Michel FOUCAULT (1984), a subjetivação é "o processo pelo qual se obtém a constituição de um sujeito, mais exatamente de uma subjetividade, que evidentemente é uma das possibilidades dadas de organização de uma consciência de si" (p. 137). A subjetividade é, assim, resultado de um processo de subjetivação, já que toda experiência que concretiza uma subjetividade envolve modos historicamente peculiares de se fazer a "experiência do si". Como bem assinala Cristiani SILVA (2006),

os sujeitos são subjetivados simultaneamente por múltiplas instâncias discursivas, que produziram diferentes 'posições de sujeito', antes mesmo de chegarem à escola. Convém lembrar também que, se há uma multiplicidade de processos constituidores de sujeitos, existem diferentes formas destes sujeitos se relacionarem, em suas existências particulares, com esses processos. Nem as práticas são homogêneas, nem as formas de vivenciá-las o são. Há sempre dobras e frestas por onde as subjetividades deslizam e fluem tornando-se singulares. O que não significa desconsiderar a importância de se analisar as redes discursivas que inscrevem determinados modos de ser dos sujeitos (p. 1).

Mesmo com todas as fragilidades que marcam este investimento cultural, persistem as intenções de se fixar modelos "normais" de masculinidade e feminilidade na vida social, e nesse processo a escola tem um papel fundamental e difícil (Guacira LOURO, 2001, p. 26). As representações que atuam no nível do corpo, construindo sujeitos, desencadeiam processos de subjetivação ao repetir e reiterar determinadas perfomances de sexo/gênero' que muitas vezes constituem modelos sexistas, etnocêntricos, racistas e classistas de subjetivação nas relações sociais. Tais "performances" são interpeladas, reafirmadas e difundidas por meio de diferentes "tecnologias de gênero" (Teresa de LAURETIS, 1994) que, como o livro didático, constituem dispositivos de subjetivação. Assim, entendemos que as representações de violência contra mulheres, difusas não só nos livros didáticos, mas em várias práticas cotidianas e institucionais, funcionam como pedagogias que prescrevem e ensinam determinados modos de ser dos sujeitos, bem como de ver, sentir e tratar essa violência no tempo presente. Não por acaso, os discursos e práticas de naturalização e banalização dessa violência se apoiam também em narrativas históricas que enraízam esse fenômeno em tempos longínquos, reiterando a sua continuidade e normalidade através dos tempos. Afinal, se a história diz que "sempre foi assim, o homem dominante e a mulher dominada", encerra-se as possibilidades futuras de existência de outros modos de subjetivação de sexo/gênero que permitam romper com as hierarquias e relações de poder que inferiorizam, excluem, oprimem e maltratam as mulheres.

Nesse sentido, destacamos a importância dos livros didáticos de História como objetos de pesquisa e análise histórica. Enquanto elementos curriculares de orientação e difusão de conhecimentos históricos a serem escolarizados, tais livros produzem e difundem representações que, atravessadas e marcadas por relações de poder, são capazes de moldar e orientar nossas maneiras de compreender, falar e se posicionar perante certos acontecimentos, sujeitos, culturas, comportamentos, instituições e relações sociais tanto do passado como do presente. Não se trata de narrativas neutras ou inocentes, pois a história se constitui como uma forma de interpretação e estabelecimento de sentidos para o passado que é sempre mediada pela cultura e interesses do presente, segundo um corpo de regras socialmente autorizadas que orientam as maneiras de ensinar, perceber, julgar, pensar e agir em relação ao passado.

A produção e circulação de representações históricas nos livros didáticos envolvem um conjunto de tradições, memórias, expectativas docentes, orientações curriculares oficiais, perspectivas historiográficas, demandas sociais, práticas, normas, valores e discursos que conformam a complexidade e especificidade do saber escolar. Diante disso, optamos por investigar as dimensões políticas e educativas das representações de violência contra mulheres nos livros didáticos. Atentando para as relações entre conhecimento, poder e subjetividades, lançamos o nosso olhar para o modo como "o conhecimento elaborado por determinado discurso se relaciona com o poder, regula condutas, inventa ou constrói identidades e subjetividades e define o modo

\footnotetext{
' Segundo Judith BUTLER (2003), a "identidade de gênero" não é de maneira alguma estável, natural ou pré-discursiva,
} pois o gênero é uma performance construída por uma repetição estilizada de atos (p. 200). 
pelo qual certos objetos são representados, concebidos, experimentados e analisados" (HALL, 2016, p. 27). Esse tipo de análise não tem interesse em "distribuir-lhes os prêmios e as punições de acerto e erro, de acordo com uma reta doutrina ou sã ciência" (Kazumi MUNAKATA, 2009, p. 289), mas sim em compreendê-los em sua historicidade, considerando suas múltiplas funções (Alain CHOPPIN, 2004, p. 553) e condições de produção.

Mais do que retratar a sociedade em sua história, os livros didáticos operam uma seleção e ressignificação de memórias sociais difusas em diversos espaços e produtos culturais. No entanto, a seleção destas memórias implica opções culturais, políticas, éticas, legitimação de poderes e projetos identitários, possibilitando esquecimentos, silenciamentos, negações, ênfases e destaques. Desse modo, os livros didáticos de História respondem aos interesses sociais de transmissão de um legado vinculado ao passado como parte de conhecimentos e valores tidos como necessários à formação das subjetividades.

Os livros didáticos enquanto saberes a serem ensinados passam, portanto, por um processo de didatização inscrito "em um ambiente pedagógico específico e em um ambiente regulador" (CHOPPIN, 2004, p. 554). Nesse sentido, os saberes veiculados nos livros didáticos de História "não decorrem exclusivamente de um fluxo oriundo do saber acadêmico" (Ana Maria MONTEIRO, 2009, p. 193), pois os processos de didatização envolvidos na sua produção revelam a sua especificidade e complexidade. As leituras e os posicionamentos políticos e pedagógicos de seus autores (na interpretação de orientações oficiais), bem como as políticas curriculares, as diretrizes do ENEM e dos exames vestibulares, as expectativas do público docente, as tradições sedimentadas sobre conteúdos indispensáveis e os interesses do mercado editorial atuam nos processos de elaboração das histórias veiculadas nesses livros, submetendo-os a um conjunto de regras de formatação, enunciação, estruturação e organização didática.

Destacamos que a Lei $n^{\circ} 9.394$, de dezembro de 1996, que estabelece as diretrizes e bases da educação nacional (LDB), determina que o Ensino Médio deve ser uma etapa de preparação do educando para o trabalho e a cidadania, bem como de seu aprimoramento como pessoa humana (BRASIL, 1996). Já os Parâmetros Curriculares Nacionais (PCNs) propõem que o ensino de história no nível médio tenha também por objetivo "a superação da passividade dos alunos frente à realidade social e ao próprio conhecimento". Para isso, coloca a necessidade de "levá-los ao desenvolvimento de competências e habilidades que possibilitem a compreensão da lógica dessa realidade e da construção do conhecimento" (BRASIL, 2002, p. 74). Além disso, as tradições e expectativas sociais sobre o Ensino Médio, como etapa preparatória para o vestibular, o Exame Nacional do Ensino Médio (ENEM) e o ingresso nas universidades ditam o tom exageradamente conteudista e abrangente dos livros didáticos, disputando espaço com as prescrições da LDB, dos PCNs e do PNLD.

Apesar de submetidos a múltiplas leituras, apropriações e interpretações em sala de aula, os livros didáticos de História ainda constituem a principal fonte de irradiação das interpretações e atitudes de professores/as e estudantes brasileiros/as perante o passado. Diante disso foi que elegemos como fonte de pesquisa cinco coleções didáticas aprovadas no PNLD de 2018. Por meio desse amplo programa de avaliação de livros didáticos, milhares de exemplares são comprados das editoras e distribuídos gratuitamente às escolas públicas de todo o país, o que faz com que estes livros cheguem mais facilmente ao público em geral, constituindo-se no segundo suporte de leitura mais lido no Brasil, cuja produção é o negócio mais lucrativo para a indústria editorial.

Desde a década de 1990, o PNLD vem passando por reformulações positivas importantes na abordagem do conhecimento histórico escolar sobre as mulheres, as desigualdades de gênero e, em alguma medida, sobre as violências sexuais e de gênero. Em 2015, o edital do PNLD 2018 para o Ensino Médio estabeleceu, dentre seus princípios, que as coleções submetidas à avaliação deviam:

1.1.1 promover positivamente a imagem da mulher, considerando sua participação em diferentes trabalhos, profissões e espaços de poder, reforçando sua visibilidade e protagonismo social;

1.1.2 abordar a temática de gênero, visando à construção de uma sociedade não-sexista, justa e igualitária, inclusive no que diz respeito ao combate à homo e transfobia;

1.1.3 proporcionar o debate acerca dos compromissos contemporâneos de superação de toda forma de violência, com especial atenção para o compromisso educacional com a agenda da não-violência contra a mulher[...] (BRASIL, 2015, p. 32).

A partir de embates e diálogos travados com movimentos sociais (feministas, indígenas e negros), o Estado passa a assumir esse compromisso educacional de superação da violência contra as mulheres e da "violência correlata" às relações étnico-raciais, ao preconceito e à discriminação racial ${ }^{2}$ (BRASIL, 2015, p. 32). Isso significou, especialmente para as mulheres, uma conquista fundamental ao reconhecimento e legitimação das lutas e reivindicações por igualdade de gênero no presente. Contudo, as formas de inclusão da história das mulheres e das relações de

\footnotetext{
${ }^{2}$ Nesse processo destacamos a conquista das Leis 10.639/03 e 11 1.645/08 no estabelecimento da obrigatoriedade do ensino de história e cultura afro-brasileira, africana e indígena nas escolas de educação básica.
} 
gênero nos livros didáticos dependem não só do modo como as prescrições oficiais são interpretadas e ressignificadas, mas também de um sistema de representações, valores, crenças e formas culturais que não é facilmente atingido nos processos oficiais de regulamentação e avaliação dos livros didáticos no Brasil. Como bem disseram Maria Inês Sucupira STAMATTO e Flávia Eloisa CAIMI (2016),

não existe um livro didático perfeito ou ideal, porque as demandas e expectativas sobre ele são muitas e diversificadas. Esse suporte cultural tem atravessado décadas e séculos sem ter sua estrutura seriamente ameaçada, possivelmente porque congrega qualidades e funcionalidades que são valorizadas no âmbito escolar (p. 244).

Assim, entendemos que condenar, queimar, ignorar ou excluir os livros didáticos não vai resolver os problemas enraizados em nossa cultura. Pelo contrário, vai continuar "escondendo", colocando à margem do debate em sala de aula as questões relacionadas à historicidade do sexo/gênero e da violência (Susane Rodrigues de OLIVEIRA, 2014, p. 288). À luz de estudos feministas interseccionais, proponho aqui outros modos de apropriação, leitura e interpretação das representações de violência contra mulheres identificadas nos livros didáticos de História, tendo em vista um ensino de história para a cidadania e o combate à violência contra mulheres em nossa sociedade. Esse exercício possibilita ainda a compreensão das dificuldades, problemas, limites e desafios que envolvem a transformação de aspectos epistemológicos que estruturam o conhecimento escolar sobre a história das mulheres e das relações de gênero.

\section{Teorias feministas e interseccionalidades}

Ao tomarmos estrategicamente a "categoria mulheres" como uma categoria de análise histórica, partirmos aqui de um conjunto de teorias feministas que aponta para a pluralidade e historicidade do "ser mulher", expressa nas múltiplas conexões do sexo/gênero às diferenças de etnia, raça, classe, orientação sexual etc. O uso dessa categoria de análise impõe alguns desafios à nossa pesquisa. Na leitura dos livros didáticos de História observamos que a violência aparece de modo generalizado, atingindo homens e mulheres em vários contextos históricos.Porém, foi possível identificar uma série de enunciados que apontam para várias modalidades de violência (física, material, simbólica, psicológica e sexual) que atingem exclusivamente as mulheres em diferentes épocas e lugares. Trata-se de restrições de direitos e cidadania, inferiorização e assédio sexual no mercado de trabalho, agressões físicas no espaço doméstico, maternidade compulsória, estupro coletivo, perseguição, aprisionamento, tortura, rapto, exploração sexual, caça às bruxas, feminicídio, pobreza, intolerância religiosa, apedrejamento, castigo, colonialismo, escravidão e tráfico humano. Em cada época e lugar estas violências revelam múltiplas posições de vítimas e agressores, produzindo lugares normativos ao introduzir na relação um conjunto de representações que gera significados corporais, relacionais e subjetivos específicos sobre quem são os homens e as mulheres.Isso implica o reconhecimento da historicidade das categorias "mulheres" e "homens" e do modo como elas são construídas em relação a várias outras categorias que também se modificam (classe, raça, etnia, sexualidade, religião, nação etc).

Na análise dos livros didáticos, torna-se, portanto, bastante problemático tratar das mulheres como uma categoria homogênea inscrita em uma ordem patriarcal universal, pois como bem observou Judith Butler (2003),

se alguém "é" uma mulher, isso certamente não é tudo o que esse alguém é; o termo não logra
ser exaustivo, não porque os traços predefinidos de gênero da "pessoa" transcendam a parafernália
específica de seu gênero, mas porque o gênero nem sempre se constitui de maneira coerente
ou consistente nos diferentes contextos históricos, e porque o gênero estabelece intersecções
com modalidades raciais, classistas, étnicas, sexuais e regionais de identidades discursivamente
constituídas. Resulta que se tornou impossível separar a noção de "gênero" das intersecções
políticas e culturais em que invariavelmente ela é produzida e mantida (p. 20).

Butler destaca ainda que a ideia de um patriarcado universal teria fracassado em explicar os mecanismos de opressão de gênero em diferentes contextos culturais. Segundo a autora, "esta forma de teorização feminista foi criticada por seus esforços de colonizar e se apropriar de culturas não ocidentais, instrumentalizando-as para confirmar noções marcadamente ocidentais de opressão (BUTLER, 2003, p. 21). Nesse entendimento, buscamos apoio nos debates sobre interseccionalidades - difundidos nos estudos feministas pós-estruturalistas, ${ }^{3}$ negros, indígenas, pós-coloniais e decoloniais -, pois permitem

[...] desafiar o modelo hegemónico de Mulher universal e comprender as experiencias das mulheres pobres e racializadas como produto da intersecção dinâmica entre o sexo/gênero, a

\footnotetext{
3 "A interseccionalidade se inscreve no projeto pós-moderno de conceitualização das identidades como múltiplas e fluídas, e se encontra com a perspectiva foucaultiana do poder na medida em que ambas enfatizam os processos dinâmicos e a desconstrução das categorias normalizadoras e homogeneizantes" (VIGOYA, 2016, p. 7 [Tradução nossa]).
} 
classe e a raça em contextos de dominação construídos historicamente (Mara VIGOYA, 2016, p. 8 [Tradução nossa]).

Nessa perspectiva, o gênero deve ser visto em associação a outros marcadores sociais que funcionam como sistemas paralelos e imbricados (Patricia COLLINS, 2015, p. 14), moldando as relações de dominação e subordinação das mulheres na história. Como bem assinala Collins (2015), "levar em conta [essa] diversidade na nossa construção do conhecimento, no nosso ensino e no nosso dia a dia nos oferece um novo ângulo de visão nas interpretações de realidades pensadas como naturais, normais e 'verdadeiras'” (p. 26).

\section{Resultados e discussão}

Quando se trata de violência contra as mulheres, a tendência dominante em nosso cotidiano é a de concebê-la como violência doméstica e conjugal, apenas como fruto de relações íntimas, interpessoais e a-históricas. No entanto, na maioria das imagens e textos que identificamos em cinco livros didáticos de História, essa violência aparece bastante diluída em meio a uma série de outros dispositivos de poder que integram as formas de governabilidade presentes em diferentes tempos e espaços.

Em apenas um dos livros didáticos analisados identificamos uma representação explícita de agressões físicas no ambiente doméstico e conjugal.Trata-se de uma caricatura (Figura 1) produzida em 1817 que, na coleção Cenas da História, "representa a tragédia de uma família diante das imprudências do marido" (Cândido GRANGEIRO, 2016, v. 3, p. 13). Tal imagem vem acompanhada de um texto que trata rapidamente dos papéis assumidos por homens e mulheres no modelo de família burguesa, a partir da Revolução Industrial e Francesa. De modo generalizado, a mulher era vista como esposa e senhora absoluta do lar, identificada como "defensora dos bons costumes, mãe zelosa, sempre fiel ao esposo e crente a Deus" (GRANGEIRO, 2016, v. 3,p. 12), cuja tarefa principal era "combater os hábitos ruins, os vícios, como o consumo de bebida alcoolica, a jogatina ou qualquer forma de farra ou orgia" (GRANGEIRO, 2016, v. 3, p. 12). Já em relação aos homens, diz ainda que "o bom homem público era semelhante ao marido delicado, zeloso com a casa (a nação) e com os filhos (os cidadãos). Ao lado do texto, a caricatura é usada para mostrar as consequências de atos que são classificados como imprudentes.

A legenda da imagem traz a seguinte interpretação:

Na primeira cena em meio a uma família feliz, o marido seduz a esposa com bebida alcoolica. No segundo, o beberão encontra-se desempregado, quando falta comida e sobra desleixo na casa. A bebida por fim traz a violência e a desagregação do lar... (GRANGEIRO, 2016, v. 3, p. 12).

Os enunciados da legenda e da narrativa passam rapidamente e superficialmente pela historicidade das relações de gênero nas famílias burguesas, deixando prevalecer uma concepção tradicional e generalizada acerca das desigualdades de gênero,que associa as mulheres ao mundo privado, dos trabalhos domésticos e do controle do lar,e os homens ao mundo
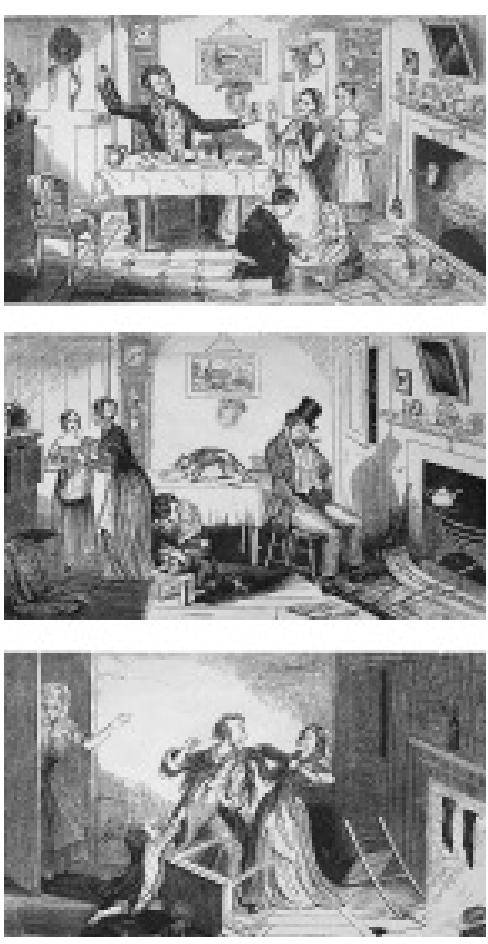

público e controle da nação.

Ao lado da caricatura, uma das questões do subtítulo "Pense e responda" chama atenção para a continuidade das desigualdades de gênero no tempo presente, lançando a seguinte pergunta: "Ainda no século XIX, como se estabeleceram os papéis de homens e mulheres? Mencione algumas desigualdades e as consequencias dessa relação para os dias atuais (GRANGEIRO, 2016, v. 3, p. 13). Desse modo,

Figura 1- A Garrafa, conjunto de caricaturas de George Kruikshank, publicado em 1817 (GRANGEIRO, 2016, v. 3, p. 13).

\#PraCegoVerA Figura 1 retrata, de modo caricatural, um acontecimento de violência contra mulheres no espaço doméstico de uma família inglesa no século XIX. Na primeira cena, um homem aparece ao centro, sentado na mesa de jantar e com uma garrafa na mão, em conversa com duas mulheres que estão de pé, ao lado da mesa. Duas crianças aparecem também brincando no cenário da sala. Na segunda cena, este mesmo homem aparece embriagado e prostrado em uma cadeira, enquanto as mulheres parecem em atividade. Na terceira cena, este homem agarra com uma das mãos o pescoço de uma das mulheres, dirigindoIhe um olhar agressivo e apontando a outra mão em punho na direção do rosto dela. Uma moça e uma criança tentam segurálo, enquanto outra mulher ingressa pela porta em socorro. A mesa e a cadeira estão reviradas no chão. 
a representação imagética de violência contra a mulher-esposa, bem como as interpretações e exercícios associados, cumprem a função de fixar no passado o estabelecimento de papéis diferenciados e desiguais para homens e mulheres em sociedade, conferindo assim explicações para a violência de gênero que chega até os dias atuais.A narrativa didática não se furta às explicações para essa violência, embora faça isso dentro dos limites daquilo que se pretende ensinar acerca da normalidade das subjetividades e relações de gênero no trabalho e no espaço doméstico.

A caricatura como fonte(imagética e textual) para a abordagem do tema da violência contra as mulheres na história pode ser bastante problemática, pois o seu aspecto lúdico e humorado pode se constituir em motivo de banalização da violência que representa.Usando do humor e/ou da violência para tratar de assuntos sensíveis referentes a determinados períodos e sociedades, as caricaturas, normalmente, são produzidas com a intenção de provocar polêmicas e reflexões, atraindo a atenção das pessoas. Por isso, para que a caricatura seja compreendida pelo receptor, é necessário conhecer as condições históricas de sua produção. As caricaturas permitem a diversão e o riso, mas precisam ser tratadas seriamente como instrumentos de ataque, denúncia ou de ridicularização, enquanto expressões de uma cultura ou modos de pensar e agir em uma determinada época e lugar. Sua exploração didática permite não só a abordagem de certos acontecimentos históricos, mas também a compreensão da crítica, da sátira e do humor que elas apresentam.

As imagens visuais, enquanto formas de comunicação, provocam sempre percepções distintas. Nos livros didáticos, as legendas, vinhetas, textos explicativos e exercícios associados às imagens têm a função de dirigir o ato de sua leitura para uma dada interpretação, o que permite observar como se orientam as leituras, interpretações e questionamentos diante de uma cena de violência contra mulheres. Desse modo, notamos que a violência contra a mulher-esposa emerge como uma forma de resolução de conflitos de uma masculinidade desviante. O homem trabalhador é visto como aquele que pode sustentar financeiramente o lar, constitui-se no modelo ideal de masculinidade. Na caricatura, o desemprego do homem-marido perturba essa ordem, causa conflitos familiares. A mulher-esposa, educada para controlar e manter a família burguesa ideal, exige do marido esse papel de mantenedor financeiro do lar. Trata-se de um modelo de família fundado em direitos e deveres baseados em uma hierarquia e desigualdade de gênero que tende a assujeitar, oprimir e violentar as mulheres. A violência, a agressividade, o trabalho e a vontade de poder aparecem, portanto, como aspectos constitutivos dos modos de subjetivação de homens brancos, burgueses, operários e heterossexuais.

As narrativas didáticas podem exercer efeitos na formação das masculinidades e feminilidades ao repetir incansavelmente histórias que expõem apenas um modelo performático de masculinidade branca-burguesa (hiperdominante, agressiva e violenta) e seu oposto de feminilidade (submissa, dócil, frágil, desprotegida e dependente). Não por acaso, predomina nos livros didáticos de História uma série de imagens que reforçam esse modelo de feminilidade hegemônico que associa as mulheres brancas-burguesas ao amor, casamento, família, serviços domésticos, gravidez, maternidade, cuidado dos outros,beleza estética e submissão ao marido; aspectos que constituem as grandes marcas da diferença de gênero e que fundamentam uma cultura de estupro e violentação das mulheres em nossa sociedade(OLIVEIRA, 2017). Tais marcas, ao serem visibilizadas e valorizadas, tornam-se referências para todos. No entanto, para que tais "marcas" se efetivem na vida social, há um investimento não só da escola, mas da família, da mídia, da igreja e outras instâncias que, como já observou Guacira Louro (2001),

realizam uma pedagogia, fazem um investimento que, frequentemente, aparece[m] de forma articulada, reiterando identidades e práticas hegemônicas enquanto subordina[m], nega[m] ou recusa[m] outras identidades e práticas; outras vezes, contudo, essas instâncias disponibilizam representações divergentes, alternativas, contraditórias (p. 25).

É assim que a narrativa didática tece sentidos para violência cometida pelo homemmarido. Ao classificá-la de forma negativa e divergente como um "ato de imprudência", reitera um modelo de masculinidade prudente e burguesa que se subjetiva, especialmente, no trabalho, distante de fatores que, como a jogatina, a farra, as orgias, os vícios e o álcool, são associados à desordem do lar e da nação e à violência contra a mulher-esposa.

Os livros didáticos analisados trazem ainda notícias de estupros de mulheres na ldade Média, cometidos por senhores feudais, cavaleiros, soldados mercenários, cruzados na guerra contra muçulmanos e bandos de homens jovens nas ruas de Veneza. A coleção História, ao tratar dos "esforços do clero para por fim à violência dos guerreiros e proteger de seus ataques o restante da sociedade desarmada"(Georgina SANTOS; Jorge FERREIRA; Ronaldo VAINFAS; Sheila FARIA, 2016, v. 1), menciona as campanhas para cristianização da cavalaria no século $X$, conhecida como Paz de Deus e que se espalhou por toda a França, onde "os cavaleiros passaram a prestar um juramento sobre relíquias sagradas em que prometiam manter a paz e proteger a sociedade e não mais invadir propriedades, saquear seus bens e estuprar mulheres" (SANTOS; FERREIRA; 
VAINFAS; FARIA, 2016, v. 1, p. 97 [Grifo nosso]). Assim, as mulheres, da mesma forma que as relíquias sagradas, as propriedades e os bens, constituíam-se em objetos de apropriação e disputa pelos homens. Apesar de apontar para a existência de um certo controle da violência dos cavaleiros cristãos, rompendo com a velha imagem da sociedade medieval como um lugar de violência descontrolada, a narrativa denota o papel inferior e o valor das mulheres naquele cenário histórico, constituindo modos de subjetivação que, mais uma vez, reiteram, de modo breve e sem qualquer explicação, o status inferior das mulheres na história. Neste caso, a preocupação central da narrativa é a de fixar na memória social a importância da cristianização dos cavaleiros medievais, ao mesmo tempo em que reitera valores e concepções sobre a paz e a violência, demarcando um modelo de masculinidade cristã que se identifica com a paz de Deus e que se forja no juramento sagrado de proteger e não estuprar as mulheres.

Nos exemplos analisados acima, notamos que as representações de violência contra as mulheres (seja na família burguesa ou nas guerras medievais) integram narrativas didáticas que promovem, sobretudo, modelos de masculinidades agressoras e protetoras em relação às mulheres.Dessa forma, perpetua-se o imaginário de que os homens que agridem as esposas só podem ser aqueles desempregados ou ligados ao vício e à jogatina. Já aqueles que estupram mulheres nas guerras só podem ser vistos como não cristãos. Não por acaso, o homem branco, casado, trabalhador e cristão, ainda é aquele que consegue se safar mais facilmente de qualquer suspeita de ser um agressor ou estuprador de mulheres em nossa sociedade,o que em muitos casos dificulta ou impede a sua criminalização e condenação no Brasil.

Ainda sobre a ldade Média, a coleção Olhares da História (José Bruno VICENTINO; Cláudio VICENTINO; 2016, v. 1) faz menção aos estupros coletivos nas noites de Veneza.Em um pequeno texto complementar, seguido de algumas questões sobre os jovens na Itália medieval, diz que

os arquivos criminais atestam numerosas práticas anômicas ou criminosas que congregam os bandos de jovens. E essas práticas, em Veneza, são características das horas noturnas. 0 estupro coletivo, diferente de muitos estupros diurnos cometidos no espaço da cidade ou da casa, inscreve-se no registro dessas violências perpetradas à noite. Os componentes lúdicos que lhe são inerentes, as injúrias e os golpes que o acompanham, seguem as regras gerais que dramatizam a conduta violenta do grupo. O estupro, como todas as outras formas de agressão noturna, prova, no seio do grupo, uma capacidade social baseada essencialmente em critérios de virilidade. A violência contra as forças policiais vale igualmente como proeza viril. A luta é exigida pelas regras da honra quando, de armas na mão, o grupo recusa-se a deixarse revistar. Mas, com frequência, a briga é voluntária, provocada por uma troca preliminar de insultos ou uma gritaria geral. Sem outra causa a não ser a escolha precisa desse adversário, observa a sentença, cinco ou seis delinquentes atacam as forças policiais do Conselho dos Dez. O jogo se prolonga. Quatro jovens, intimados a entregar suas armas, lutam de espada com um guarda, obrigam-no a refugiar-se numa casa, perseguindo-o até afinal feri-lo. [...] (apud VICENTINO; VICENTINO, 2016, v. 1, p. 244[Grifos nossos]).

Esse texto, extraído de uma obra da historiadora Elisabeth Crouzet-Pavan, explicita que o estupro praticado em grupo servia como "proeza viril" enquanto prova da capacidade social masculina-juvenil baseada em critérios de virilidade. Entretanto, o livro didático, nos usos e apropriações que faz da historiografia, ${ }^{4}$ deixa escapar a oportunidade de problematizar/historicizar os significados de tais estupros, já que o exercício que se segue ao texto tem finalidade apenas de problematizar a imagem dos jovens como violentos, insubordinados e sexualmente agressivos, colocando em debate apenas a opinião da mídia sobre isso. Assim, reitera enunciados que reforçam a ideia de estupro coletivo como prova masculina da capacidade de atuação social, ou seja, de compactuar e agir de acordo com as condutas e regras violentas de um grupo. Apesar dos estupros serem vistos como "práticas anômicas e criminosas", o texto acaba revelando as regras de grupos que se subjetivam em uma masculinidade dominadora e viril exercida por meio de uma conduta violenta, baseada em injúrias e golpes deferidos contra mulheres. Novamente, notamos que as representações de violência sexual contra mulheres integram uma ordem discursiva interessada em estabelecer modelos de masculinidades agressoras.

O texto acima não explicita diretamente quem são as vítimas de tais estupros, e por isso mesmo requer um cuidado na sua leitura e problematização em sala de aula. Esse silêncio em torno das vítimas é constitutivo também de uma tradição historiográfica de ocultação da violência de gênero, orientada por uma ordem discursiva androcêntrica e sexista que coloca esse tipo de violência à margem da história, como algo a-político e que diz respeito à vida íntima e privada. A ocultação das vítimas, seus nomes, idades, profissões, raça, região, estado civil ou religião mantém a impressão de que o estupro é parte de um desejo sexual masculino/jovem, natural e descontrolado. Além disso, a associação do estupro com a virilidade, a força e a solidariedade de grupos masculinos, cuja ação e poder se fundamentam na violência, encontra ressonâncias em práticas e discursos de

${ }^{4}$ Com isso, é importante ressaltar que não estamos colocando em questionamento e análise a obra de Elisabeth Crouzet-Pavan. Entendemos que a análise de qualquer fragmento historiográfico necessita ser contextualizada, tendo como referência o conjunto da obra em que se insere. 
nosso cotidiano, haja vista a enorme quantidade de notícias de estupros coletivos no Brasil, cometidos especialmente por grupos de homens jovens. Assim, são reiteradosos modelos tradicionais de subjetivação de homens jovens em situações de poder e conflito, bem como o silêncio, a indiferença, a tolerância e o descaso em relação aos estupros coletivos.

No que se refere à história do Brasil República, uma narrativa sobre a Guerra de Canudos (1896-1897), exposta no segundo volume do livro Oficina de História, faz menção ao estupro dentre as "cenas de extremo horror" retratadas pelos jornalistas que acompanharam a última expedição militar a Canudos em 1897. Segundo os autores, muitos foram assassinados e tiveram seus corpos queimados, mas "como de horror foi o destino das meninas da comunidade, vítimas de estupro e muitas delas obrigadas pelos soldados a se prostituir" (Flávio de CAMPOS; Júlio Pimentel PINTO; Regina CLARO, 2016, v.2, p. 254 [Grifo nosso]).

As evidências de estupros, lançadas brevemente nos livros didáticos, sem qualquer problematização ou historicização, funcionam também como tecnologias sociais da perfomatividade do sexo/gênero, ajudando a perpetuar o caráter de normalidade da violência sexual em cenários de guerra.De acordo com Rita SEGATO (2016), a violência sexual deve ser tratada como uma forma de "violência por meios sexuais" (p. 144), pois precisamos romper com o imaginário que tende a sexualizar o estupro, especialmente em cenários bélicos. Nesse tipo de violência não está em jogo a satisfação sexual, ou uma necessidade sexual dos homens, mas sim uma satisfação do poder, já que o estupro se expressa como um ato de empoderamento masculino sob o corpo das mulheres. A expressão da derrota do inimigo, simbolizando a sua destruição como força de respeito e poder, também se dá sobre os corpos das mulheres que constituem objetos de anexação, estupro ou sequestro como escravas, concubinas ou prostitutas, enquanto subprodutos da guerra (SEGATO, 2016, p. 162).

Não por acaso, a narrativa didática sobre a Guerra de Canudos confere destaque ao poder, agressividade e protagonismo do Estado, fazendo menção à violência sexual contra as mulheres. Sem a problematização ou condenação dessa violência, a narrativa tende a reforçar no imaginário a legitimação dessa prática como forma legítima de expressão de poder e soberania do Estado. A representação do estupro emerge, portanto, para re-afirmar a identidade do Estado, fundamentada em um modelo de masculinidade dominante e sexualmente agressora de mulheres. A festa e o sentimento de celebração que se seguem com a derrota de Canudos convertem o estupro em instrumento de guerra legítimo e aceitável na história. Nada é dito sobre as vítimas dessa violência, especialmente sobre o protagonismo e importância destas mulheres em Canudos,perpetuando um silêncio que lhes nega existência e humanidade na história. É assim que, na vida social, os estupros e assédios sexuais ainda ganham valor nos modos de subjetivação dos homens no governo, poder e controle social.

Em um exercício presente na coleção História Global, solicita-se a leitura de um pequeno relato das "monstruosidades" contra crianças e mulheres judias nos campos de concentração nazista na Segunda Guerra Mundial. Assim diz:

[...] os sobreviventes se recordam primeiro das crianças. Falam dos bebês arremessados vivos nos crematórios, dos moribundos corroídos pelas doenças injetadas pelo médico de Auschwitz, doutor Josef Mengele; dos concursos de arremessos de crianças judias entre os guardas da SS. Também falam das mulheres; as mais jovens estupradas repetidamente antes de mortas, seus corpos usados como tochas humanas em fogueiras de mortos - a carne delas, constataram os guardas, queima mais rápido. Quando pergunta-se sobre as pilhas de corpos, as testemunhas lembram de ratazanas mordiscando os cadáveres; de prisioneiros ainda vivos lutando para se expelir de uma montanha de mortos; de mulheres grávidas abortando fetos. E do cheiro, dizem todos. II Guerra Mundial. Fábrica da Morte [Revista Veja On-line, 2016] (Gilberto COTRIM, 2016, v. 3 , p. 333 [Grifos nossos]).

Em seguida o livro lança a seguinte questão para debate: "Quais seriam as origens da violência e da maldade?". O Manual do Professor chama atenção pela resposta que confere a essa indagação, ao classificá-la como pessoal e justificar que se trata de um tema "complexo e de amplitude filosófica", propondo que "os estudantes devem conversar com os professores de Filosofia e Sociologia e, tanto quanto possível, ler autores que tratam do tema (Konrad Lorenz, Hannah Arendt, Sigmund Freud etc.)" (COTRIM, 2016, v. 3, p. 333). Desse modo, retira-se da história e dos professores de história a responsabilidade de oferecer qualquer explicação para essa violência. Ao descrevê-la como algo complexo e de amplitude filosófica, retira-se a historicidade da violência, ou seja, retira-se a sua dimensão temporal, o seu entendimento como algo que não é arbitrário ou natural, mas sim fruto de um processo histórico, de uma trama vital que provém do passado. Isso acontece também em boa parte dos discursos cinematográficos sobre a Segunda Guerra Mundial, onde a violência sexual perpetrada por soldados contra mulheres inimigas perde toda a carga de historicidade, já que mostrada como simples resultado da insanidade, sadismoou desejos sexuais masculinos reprimidos, pervertidos e insaciáveis. Boa parte dos filmes mostra, portanto, o exercício dessa violência sexual como algo simplesmente patológico, lúdico ou sexualmente natural para os soldados agressores. Desse modo, as narrativas didáticasse inscrevem 
também em uma tradição de memórias assentadas em um modelo patriarcal e racista de subjetivação de homens e mulheres em cenários de guerra. A falta de uma perspectiva histórica para o tratamento dessa questão se deve ainda à própria epistême dominante no campo do conhecimento histórico escolar que não comporta a inclusão do gênero e da raça como categorias interseccionais de análise histórica.

É nesta perspectiva que a coleção História cita rapidamente os estupros cometidos contra mulheres indígenas pelos espanhóis na conquista da América. Ao tratar do colapso da população indígena na América, narra que

os espanhóis foram tão violentos contra os índios como os europeus o eram em suas guerras, mutilando, estuprando, torturando. No caso da América, está provado que a tremenda crise demográfica indígena se deveu, antes de tudo, às epidemias de varíola (SANTOS; FERREIRA; VAINFAS; FARIA, 2016, v. 1, p. 245 [Grifo nosso]).

Neste enunciado, os estupros contra mulheres indígenas se inscrevem na continuidade das ações dos europeus nas guerras. Além disso, aparecem dissociados do declínio da população indígena em tempos coloniais, já que o destaque é dado às doenças. Nessa perspectiva, a narrativa silencia uma série de fatores, especialmente, os efeitos colaterais das guerras de conquista, onde os estupros sistemáticos inseminavam as mulheres indígenas, engravidando-as forçadamente, promovendo genocídios sem derramamento de sangue. O estupro, novamente, emerge com a função de destacar a normalidade dos modos de atuação dos homens europeus nas guerras e, por conseguinte, nas relações de dominação dos indígenas na América.

As opressões de raça e gênero estão imbricadas na violência do estupro de mulheres indígenas pelos europeus. De acordo com a feminista indígena Andrea SMITH (2014), quando uma mulher "indígena sofre abuso, isso é um ataque à sua identidade como mulher e à sua identidade como indígena. As questões de opressão por colonização, raça ou gênero não podem ser vistas separadamente" (p. 196-197). Em algumas sociedades indígenas da América, a hierarquia e a violência de gênero eram muitas vezes inexistentes. Na ótica dos homenscolonizadores, as mulheres indígenas eram assim "portadoras de uma ordem anti-imperial e representa[va]m uma grande ameaça à cultura dominante" (SMITH, 2014, p. 204). Desse modo, o controle simbólico e literal dos corpos de tais mulheres foi muito importante na guerra contra os indígenas, pois tinha a finalidade de introduzir a hierarquia e a dominação no corpo dos colonizados (SMITH, 2014, p. 204).

Isso explica enunciados, como o que aparece na coleção Olhares da História, que expõem diferenças no destino das mulheres e homens indígenas que haviam lutado nos movimentos de resistência ao colonialismo português na chamada "Guerra dos Bárbaros" no século XVII, no nordeste brasileiro. O enunciado diz que "depois das batalhas, os prisioneiros mais fortes foram exterminados a ferro frio, as mulheres e as crianças eram escravizadas e enviadas para as fazendas para indenizar os proprietários de terra dos custos da 'guerra justa'" (VICENTINO; VICENTINO, 2016, v. 2, p. 99).

Já a coleção História Global também reforça essa concepção ao tratar da escravidão indígena na América, expondo uma imagem (Figura 2) produzida em 1834 por Jean-Baptiste Debret, onde a legenda diz "Família de indígenas capturada e escravizada por bandeirantes" (COTRIM, 2016, v. 1, p. 254).

Não por acaso, tais enunciados apresentam um silêncio significativo em torno das razões dessa violência particular contra as mulheres indígenas em tempos coloniais. Como resultado de uma tradição epistêmica que se faz presente na escrita da história escolar, as mulheres indígenas são subjetivadas como escravas, empregadas domésticas e prostitutas, como seres desprovidos de privilégios, direitos humanos e direitos trabalhistas. Desse modo, as representações de violência contra mulheres indígenas apenas expõem as relações assimétricas e de dominação em favor dos conquistadores europeus, diminuindo ou ocultando outras possibilidades de existência para estas mulheres, especialmente na resistência à dominação colonial. Como também analisou Mauro César COELHO (2009), nos livros didáticos de História produzidos entre 1992 e 2005 ,

Figura 2 - Litografia de Charles Motte sobre desenho de Jean-Baptiste Debret, produzida em1 834 (COTRIM, 2016, v. 1, p. 254).

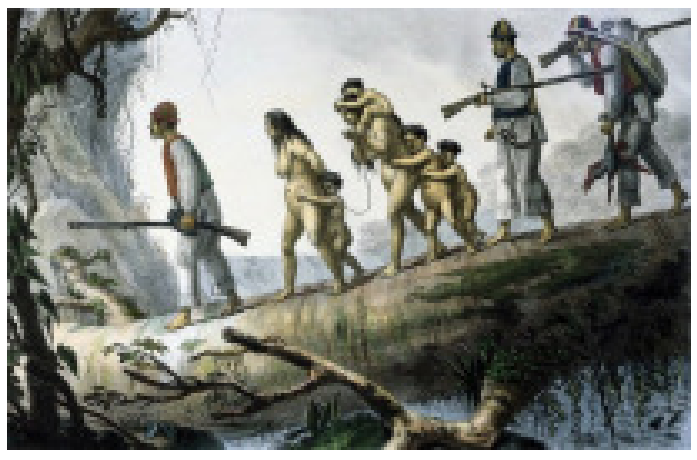

\#PraCegoVer A figura 2 revela duas mulheres indígenas nuas que, acompanhadas por quatro crianças indígenas, são conduzidas para a escravidão acorrentadas no meio da selva, por três homens portadores de armas de fogo. 
a consideração de que a função da história é a conscientização das reais condições de existência, por meio da exposição das injustiças cometidas, está pautada em uma visão unilateral do passado. É a preocupação com a conscientização que organiza a perspectiva adotada. Assim, as representações sobre os índios obedecem àquele imperativo: ensinar sobre o passado brasileiro significa expor as injustiças cometidas e dimensioná-las, evidenciando os males causados por elas e as razões de terem ocorrido (2009, p. 278 [Grifo original]).

Desse modo, a educação escolar, por meio de narrativas históricas difundidas nos livros didáticos,traduz apenas o ponto vista dos grupos dominantes,colaborando em processos de subjetivação que tendem a manter uma ordem socioeconômica hierárquica baseada em desigualdades de gênero/raça, criadas a partir da expansão colonial, em 1492.

As ações de dominação e poder dos sujeitos masculinos-brancos-europeus ainda constituem o eixo central das narrativas didáticas onde emerge a violência contra mulheres indígenas. Os enunciados dessa violência cumprem apenas a função de reforçar no imaginário dos/as estudantes a vitimização e inferiorização das mulheres indígenas e seu contrário, a superioridade e o poder dos homens-brancos-europeus-colonizadores na história. Contudo, perdese de vista o sentido de violência e desumanidade de tais atos, já que nessa ordem discursiva não há espaço para o questionamento do racismo/sexismo intrínseco aos modos de subjetivação destas mulheres na história. As narrativas didáticas tendem assim a incluí-las de modo desigual e marginalizado, como corpos vitimizados e aparentemente sem história, cujo valor se manifesta apenas como objeto de posse e dominação colonial/patriarcal.

Já a coleção História Global,ao tratar das mulheres negras nas Minas Gerais, no período da escravidão, diz que as mulheres escravizadas "suportariam uma dupla exploração: sexual e econômica" e que, assim, a "escravidão revelaria uma de suas faces mais severas" (COTRIM, 2016 , v. 2, p. 337). Nesta narrativa, a violência sexual aparece como uma forma de"exploração", tal qual a exploração da terra e do trabalho. Já o silêncio sobre os modos de funcionamento do estupro no sistema escravista apenas reforça as injustiças e vitimização das mulheres negras na história, sobretudo, as imagens racistas/sexistas de corpos hiperssexuados capazes de"suportar" todo tipo de abuso e violência sexuais. Afinal, nada é dito sobre aquelas que não "suportaram" tal situação, seja resistindo ou sucumbindo aos maus tratos extremos. A imagem generalizada das mulheres negras como seres que "suportam" essa violência da exploração sexual e econômica é também constitutiva dos modos de assujeitamento, exploração, subordinação e violentação destas mulheres no tempo presente. Desse modo, as representações de mulheres negras em situação de violência tendem a perpetuar o racismo/sexismo estrutural da sociedade brasileira.

$\mathrm{Na}$ ordem colonial e escravista, as mulheres indígenas e negras foram vistas e tratadas como "fêmeas", classificadas como seres que possuem "sexo" e "natureza" (Maria LUGONES, 2014), em oposição àqueles que possuem "humanidade" e "gênero (classificados como homens ou mulheres). Segundo Angela Davis (2013),

como fêmeas, as mulheres escravas estavam inerentemente vulneráveis a todas as formas de coacção sexual. Se a mais violenta punição dos homens consistia nos castigos e mutilações, as mulheres eram castigadas e mutiladas, bem como violadas. A violação, de facto, era uma expressão demonstrada pelo domínio econômico dos donos de escravos e pelo controle do capataz sobre as mulheres negras como trabalhadoras. Os especiais abusos assim infligidos sobre as mulheres facilitavam a crueldade da exploração econômica do seu trabalho. As exigências desta exploração fizeram com que os donos de escravos pusessem de lado as suas atitudes sexistas ortodoxas nas propostas de repressão(p. 12).

bell hooks (2014) explica que a exploração sexual das mulheres escravizadas representava um direito e privilégio dos homens brancos (donos de escravos) que estavam no poder. Já a resistência dessas mulheres à exploração sexual se constituía em uma forma de desafio ao sistema, "a sua recusa em submeterem-se passivamente à violação era a marginalização do direito dos donos dos escravos sobre si mesmas. Elas foram brutalmente punidas" (hooks, 2014, p. 21). A autora diz que "o objetivo da política desta violação categórica das mulheres negras pelos homens brancos era obter absoluta lealdade e obediência à ordem imperialista branca" (hooks, 2014, p. 21). Desse modo, reitera as análises de Angela Davis, para quem o estupro das mulheres escravizadas não era resultado da "satisfação da luxúria sexual dos homens brancos, mas era de facto um método institucionalizado de terrorismo que atingiu o seu objetivo de desmoralizar e desumanizar as mulheres negras" (hooks, 2014, p. 21).

Ao denunciar as "barbaridades" cometidas pelos senhores contra as mulheres negras escravizadas, uma caricatura (Figura 3), publicada na Inglaterra como propaganda antiescravista de 1971, é reproduzida na coleção História.Tratando com ironia os níveis de crueldade com que as mulheres negras eram submetidas na ordem escravista, a legenda diz que "um senhor joga uma escrava em um tacho fervendo com caldo de cana-de-açúcar" (SANTOS; FERREIRA; VAINFAS; FARIA, 2016, v. 2, p. 198). Já o texto que acompanha essa imagem destaca apenas o protagonismo dos homens europeus e norte-americanos que, como intelectuais, representantes do parlamento e 
dos interesses econômicos britânicos, foram responsáveis pela extinção do tráfico de escravos e a abolição da escravatura no Atlântico.

Devemos assinalar que os abolicionistas difundiram uma série de imagens reveladoras da violência desmedida da escravidão e que subjetivavam, especialmente, as mulheres negras como corpos de extrema exploração e de sujeição à violência dos senhores de escravos. Mesmo com a abolição da escravatura estas imagens foram pouco questionadas e historicizadas. Por se tratar de uma caricatura que enfatiza e exagera as características das pessoas, de uma forma bastante irônica e ridicularizada, torna-se necessário problematizar o seu conteúdo em sala de aula, para que o riso e a diversão não cedam lugar a uma banalização da violência que a imagem representa. Sua característica de propaganda antiescravista no século XVIII necessita ser explicitada, já que se trata de uma imagem que implica processos de subjetivação das mulheres negras como corpos passíveis de dor, sofrimento, exploração extrema e destruição. Para isso, a imagem precisa ser abordada como fonte histórica e não como mera ilustração de acontecimentos, como bem orientam os PCNs. No entanto, nos usos e apropriações dessa imagem no livro didático,observamos a presença de uma tradição epistêmica positivista que,ao incorporaras imagens como reflexos fiéis do passado, tende a perpetuar apenas o ponto de vista daqueles que dominaram o campo das representações da escravidão e da abolição.

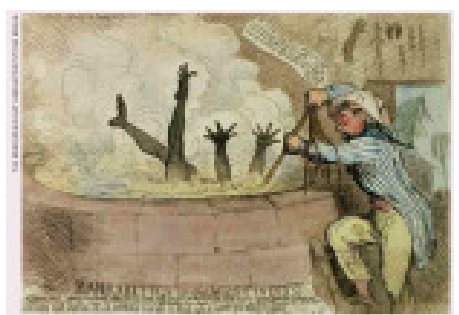

Figura 3 - Caricatura de James Gilbray, datada de 1791. Propaganda antiescravista (SANTOS; FERREIRA; VAINFAS; FARIA, 2016, v. 2, p. 198).

\#PraCegoVer A Figura 3 traz uma legenda intitulada Barbaridades das Índias Ocidentais. Esta caricatura antiescravagista mostra um homem branco cozinhando o corpo de uma mulher negra/escravizada em um tanque com caldo de cana-de-açúcar.

A narrativa que acompanha essa imagem revela ainda a presença de uma tradição historiográfica brasileira sobre o tema da abolição que,ao silenciar o protagonismo dos/as negros/ as nos movimentos abolicionistas, tende a subjetivar apenas os homens brancos, representantes das elites dirigentes da nação, em atividades intelectuais, literárias, jornalísticas e políticas relacionadas à abolição da escravatura(Ana Flávia Magalhães PINTO, 2018).Apesar de incluir as mulheres negras e o tema da propaganda antiescravista, tendo em vista as demandas colocadas pela Lei 10.639/ 03 de inclusão do ensino de história e cultura africana e afrobrasileira nas escolas, essa narrativa deixa também escapar a resistência e o protagonismo das mulheres negras no processo de abolição. A exposição deste protagonismo faria funcionar outra ordem discursiva e epistêmica na escrita da história escolar,promotora de modos de subjetivação positivos e emancipadores para as mulheres negras na história e que colocariam em questionamento a visão histórica racisła/sexista que reafirma o protagonismo e superioridade dos homens brancos (norte-americanos e britânicos) como os verdadeiros heróis da abolição da escravatura. Desse modo, o livro didático expõe uma imagem cruel - sexista e racista - que hoje, dentre tantas outras que circulam em nossa sociedade, tende a fixar/naturalizar a inferioridade, a subordinação e opressão das mulheres negras.

\section{Considerações finais}

Na análise dos livros didáticos de História podemos compreender as enormes dificuldades, limitações e desafios que envolvem a transformação das representações de violência contra mulheres nos saberes escolares, pois permanecem assentadas não só em valores, crenças e imaginários dominantes em nossa sociedade, mas também em uma tradição epistêmica sexista e racista, comum aos discursos e práticas estruturantes da sociedade brasileira. Assim, entendemos que o compromisso educacional de "superação de toda forma de violência" (BRASIL, 2015), como bem prescreve o PNLD (2018), exige novos conteúdos, novos métodos e novas epistemologias para os saberes escolares.

Já que os livros didáticos não problematizam ou historicizam os enunciados de violência contra mulheres, cabe aos/às professores/as essa tarefa em sala de aula, lançando questionamentos que possibilitem a difusão de uma concepção onde o sexo/gênero seja compreendido não como uma dimensão particular/privada da existência humana, mas sim pública, política e de impacto geral na história das coletividades. Apontar o caráter histórico-cultural, interseccional e sistêmico da violência de sexo/gênero na história constitui uma estratégia didática fundamental de combate e desconstrução dos esforços do patriarcado em invisibilizar, privatizar ou naturalizar todas as formas de violência contra mulheres.A história é uma poderosa ferramenta para mudar a cultura e criar mudanças sociais. As abordagens e reflexões sobre o tema da violência contra mulheres no ensino de história podem assim se constituir em um apelo à ação, a não aceitação passiva dos atentados à dignidade física, mental ou moral das mulheres no tempo presente. 


\section{Referências}

BRASIL. Edital de convocação para o processo de inscrição e avaliação de obras didáticas para o Programa Nacional do Livro Didático- PNLD 2018. Brasília: MEC/SEC/SECADI; FNDE, 2015.

BRASIL. LDB - Lei $n^{\circ}$ 9394/96, de 20 de dezembro de 1996. Estabelece as diretrizes e bases da Educação Nacional. Brasília: MEC, 1996.

BRASIL.Orientações Educacionais Complementares aos Parâmetros Curriculares Nacionais Ensino Médio (PCN+ Ensino Médio). Brasília: MEC, 2002.

BUTLER, Judith. Problemas de gênero: feminismo e subversão da identidade. Rio de Janeiro: Civilização Brasileira, 2003.

CAIMI, Flávia Eloisa; STAMATTO, Maria Inês Sucupira. "O Livro Didático de História do Ensino Médio: critérios de avaliação e documentos curriculares". Revista Educação em Questão, Rio Grande do Norte, v. 54, n. 41, mai/ago. 2016.

CAMPOS, Flávio de; PINTO, Júlio Pimentel; CLARO, Regina. Oficina de História. 2. ed. São Paulo: Leya, 2016.

CHOPPIN, Alain. "História dos livros e das edições didáticas: sobre estado da arte". Educação e Pesquisa, São Paulo, v. 30, p.549-566, set./dez. 2004.

COELHO, Mauro César. "A história, o índio e o livro didático: apontamento para uma reflexão sobre o saber histórico escolar". In: ROCHA, Helenice Aparecida Bastos; REZNIK, Luís; MAGALHÃES, Marcelo de Souza. A História na Escola: autores, livros e leituras. Rio de Janeiro: EDFGV, 2009. p. 263-280.

COLLINS, Patricia Hill. "Em direção a uma nova visão: raça, classe e gênero como categorias de análise e conexão”. In: MORENO, Renata (Org.). Reflexões e práticas de transformação feminista. São Paulo: EDSOF, 2015. p. 13-42.

COSTA, Fernando Sánchez. "La cultura histórica. Una aproximación diferente a la memoria colectiva". Pasado y Memoria:Revista de Historia Contemporánea, Alicante, n. 8, p. 267-286, 2009.

COTRIM, Gilberto. História global. 3.ed. São Paulo: Saraiva Educação, 2016.

DAVIS, Angela. Mulher, raça e classe. Lisboa: Plataforma Gueto, 2013.

FOUCAULT, Michel. "O retorno da moral. Barbedette, Gilles e Scala, André". Entrevista de Michel Foucault. Les Nouvelles, em 29/5/1984. In: ESCOBAR, Carlos Henrique (Org.). Michel Foucault (19261984). O Dossier: últimas entrevistas. Rio de Janeiro: Livraria Taurus Editora, 1984. p. 128-138.

GRANGEIRO, Cândido. Cenas da história. 1. ed. São Paulo: Palavras Projetos Editoriais, 2016.

HALL, Stuart. Cultura e representação. Rio de Janeiro: EDPUC; Apicuri, 2016.

hooks, bell. Não sou eu uma mulher. Mulheres negras e feminismo. Lisboa: Plataforma Gueto, 2014.

LAURETIS, Teresa de. "A tecnologia de gênero". In: HOLLANDA, Heloísa Buarque de (Org.). Tendências e impasses: o feminismo como crítica da cultura. Rio de Janeiro: Rocco, 1994. p. 206-242.

LOURO, Guacira Lopes. “Pedagogias da sexualidade”. In: LOURO, Guacira Lopes. O corpo educado. Pedagogias da sexualidade. Belo Horizonte: Autêntica, 2001. p. 07-34.

LUGONES, Maria. "Rumo a um feminismo descolonial". Revista Estudos Feministas, Florianópolis, v. 22, n. 3, p. 935-952, set. 2014.

MONTEIRO, Ana Maria. "Professores e livros didáticos: narrativas e leituras no ensino de história". In: ROCHA, Helenice Aparecida Bastos; REZNIK, Luís; MAGALHÃES, Marcelo de Souza.A História na Escola: autores, livros e leituras. Rio de Janeiro: EDFGV, 2009. p. 177-2009.

MUNAKATA, Kazumi. "Devem os livros didáticos de história ser condenados?". In: ROCHA, Helenice; MAGALHÃES, Marcelo; GONTIJO, Rebeca (Org.). A escrita da história escolar: memória e historiografia. Rio de Janeiro: EDFGV, 2009. p. 281-292.

OLIVEIRA, Susane Rodrigues de. "Ensino de história das mulheres: reivindicações, currículos e potencialidades". In: STEVENS, Cristina; OLIVEIRA, Susane; ZANELLO, Valeska; SILVA, Edlene; PORTELA, 
Cristiane. Estudos Feministas e de Gênero: Articulações e Perspectivas. Florianópolis: Editora Mulheres, 2014. p. 276-291.

OLIVEIRA, Susane Rodrigues de. "O dispositivo amoroso e o assujeitamento das mulheres nas histórias que os livros didáticos ensinam". In: STEVENS, Cristina; OLIVEIRA, Susane; ZANELLO, Valeska; SILVA, Edlene; PORTELA, Cristiane (Org.). Mulheres e violências: interseccionalidades. Brasília: Technopolitik, 2017. p. 205-225.

PINTO, Ana Flávia Magalhães. Escritos de liberdade: literatos negros, racismo e cidadania no Brasil oitocentista. Campinas: EDUnicamp, 2018.

SANTOS, Georgina Silva dos; FERREIRA, Jorge; VAINFAS, Ronaldo; FARIA, Sheila de Castro. História. 3.ed. São Paulo: Saraiva Educação, 2016.

SEGATO, Rita Laura. La guerra contra las mujeres. Madri: Traficante de Sueños, 2016.

SILVA, Cristiani Bereta. "Gênero e sexualidade nos livros didáticos de História: algumas questões sobre produções de subjetividades". In: SEMINÁRIO INTERNACIONAL FAZENDO GÊNERO,7, 2006, Florianópolis, UFSC. Anais eletrônicos, Florianópolis: UFSC, p. 1-8,2006.

SMITH, Andrea. "A Violência Sexual como uma Ferramenta de Genocídio". Espaço Ameríndio, Porto Alegre, v. 8, n. 1, p. 195-230, 2014.

VICENTINO, José Bruno; VICENTINO, Cláudio. Olhares da História: Brasil e Mundo. $1^{a}$ ed. São Paulo: Editora Scipione, 2016.

VIGOYA, Mara Viveros."La interseccionalidad: una aproximación situada a la dominación".Debate Feminista, Ciudad de México, v. 52, p. 1-17, out. 2016.

Susane Rodrigues de Oliveira (susanero@gmail.com) é professora do Departamento de História e do Programa de Pós-Graduação em História da Universidade de Brasília. É historiadora, com Mestrado e Doutorado em História pela UnB. Em 2018, realizou estágio pós-doutoral no Instituto de Investigaciones Feministas da Universidad Complutense de Madrid e no Departamento de História da UNICAMP.

COMO CITAR ESSE ARTIGO DE ACORDO COM AS NORMAS DA REVISTA

OLIVEIRA, Susane Rodrigues de. "Violência contra mulheres nos livros didáticos de História (PNLD 2018)". Revista Estudos Feministas, Florianópolis, v. 27, n. 3, e58426, 2019.

\section{CONTRIBUIÇÃO DE AUTORIA}

Não se aplica

FINANCIAMENTO

Não se aplica

\section{CONSENTIMENTO DE USO DE IMAGEM}

Não se aplica

APROVAÇÃO DE COMITÊ DE ÉTICA EM PESQUISA

Não se aplica

\section{CONFLITO DE INTERESSES}

Não se aplica

LICENÇA DE USO

Este artigo está licenciado sob a Licença Creative Commons CC-BY International. Com essa licença você pode compartilhar, adaptar, criar para qualquer fim, desde que atribua a autoria da obra. 


\section{HISTÓRICO}

Recebido em 30/07/2018

Reapresentado em 30/01/2019

Aprovado em 22/04/2019 